\title{
Acetic Acid Fermentation of Soybean Molasses and Characterisation of the Produced Vinegar
}

\section{Lucas Caldeirão Rodrigues Miranda'•, Rodrigo José Gomes'®, José Marcos Gontijo Mandarino, Elza louko Ida'๑ and Wilma Aparecida Spinosa ${ }^{1 *}$ (อ}

'Department of Food Science and Technology, Londrina State University, Celso Garcia Cid (PR 445) Road, 86057-970, Londrina, PR, Brazil ²Embrapa Soybean, Carlos João Strass Road, 86001-970, Londrina, PR, Brazil

Received: 17 March 2019 Accepted: 3 February 2020
*Corresponding author:

Phone: +554333714585

Fax: +554333284440

E-mail:wilma.spinosa@uel.br

\begin{abstract}
SUMMARY
Soybean molasses is a by-product from the production of protein concentrate from soybean meal that predominantly contains sugars, with sucrose as the major component. In Brazil, soybean molasses is used for animal feed or it is discarded, although some industries use it to produce ethanol. This study aims to evaluate the parameters required for the acetic acid fermentation of soybean molasses, and characterise the resultant vinegar. To study the most suitable parameters for the acetic acid fermentation, vinegar was produced from the alcoholic fermentation of soybean molasses through eight fermentation cycles: five for adaptation and three for production. The average acidity of the acetic acid fermentation product was $50.60 \mathrm{~g} / \mathrm{L}$, with an acetic acid fermentation yield, total yield of acetic acid in broth and productivity $65.01 \%, 92.76 \%$ and $0.033 \mathrm{~g} /(\mathrm{L} \cdot \mathrm{h})$, respectively. The vinegar produced from soybean molasses had an acidity of $5.07 \%(\mathrm{~m} / \mathrm{V})$, residual ethanol content $0.17 \%(\mathrm{~m} / \mathrm{V})$, sugars $7.86 \%(\mathrm{~m} / \mathrm{V})$, dry extract $14.67 \%(\mathrm{~m} / \mathrm{V})$, ash $2.27 \%(\mathrm{~m} / \mathrm{V})$ and a density of $1.023 \mathrm{~g} / \mathrm{cm}^{3}$. The contents of total phenolics and isoflavones decreased after the alcohol and acetic acid fermentations. Moreover, the isoflavone profile of the fermented product comprised only three forms: daidzein, glycitin and genistin. According to our results, $3460 \mathrm{~L}$ of vinegar can be produced for every tonne of soy molasses, with an acetic acid concentration of $40 \mathrm{~g} / \mathrm{L}$, the minimum required by the legislation on vinegar production. Thus, these findings demonstrate that soy molasses represents a useful raw material for the production of vinegar.
\end{abstract}

Key words: vinegar, acetic acid fermentation, soybean molasses, by-product of soybean processing

\section{INTRODUCTION}

Soybean molasses is a viscous, brown and bittersweet liquid, obtained from the processing of soy protein concentrates. The soy proteins are concentrated from defatted soybean meal by ethanol washing, a procedure that promotes the extraction of soluble carbohydrates and other water-soluble compounds. Sugars are then concentrated via the evaporation of ethanol and the partial evaporation of water, resulting in the production of soybean molasses (1). Sucrose, raffinose and stachyose are the main sugars in the molasses, which also contains proteins, lipids, minerals and isoflavones $(1,2)$. A large portion of this by-product is used for animal feed or discarded. In Brazil, however, some soybean processing industries use soybean molasses to produce hydrated alcohol, because sucrose is the predominant sugar and it can be fully metabolised by the yeast Saccharomyces cerevisiae. In contrast, raffinose and stachyose cannot be metabolised by $S$. cerevisiae, as it lacks the $a$-galactosidase enzyme necessary to hydrolyse the a-1,6-glycosidic bonds of these sugars $(1,3)$.

The isoflavones are the main phenolic compounds present in soybean and its products. These compounds are distributed in aglycone forms (daidzein, genistein and glycitein) and their respective $\beta$-glucoside (daidzin, genistin and glycitin), acetyl-glucoside (6"-O-acetyl-daidzin, 6"-O-acetyl-genistin and 6"-O-acetyl-glycitin) and malonyl-glucoside conjugates (6"-O-malonyl-daidzin, 6"-O-malonyl-genistin and 6"-O-malonyl-glycitin), 
totalling twelve different forms (4). According to Handa et al. (5), the glycosidic forms are predominant in soybeans, constituting $50-90 \%$ of the total isoflavones. It is reported that these isoflavones, mainly the aglycones, have biological activity. Moreover, they have attracted attention because of their ability to reduce the risk of cardiovascular diseases, inhibit cancer cell growth, prevent diseases, such as osteoporosis, and alleviate the symptoms of menopause (5).

Vinegar is a food condiment produced by a double fermentation: an initial alcoholic fermentation, followed by an acetic acid fermentation, for which amylaceous or sugary raw materials can be used (6-9). In biochemical terms, acetification is an oxidation process carried out by acetic acid bacteria ( $A A B)$. However, the process of vinegar production is commonly referred to as a fermentation and it can be performed in three different ways: slow, fast and submerged $(8,10)$. The submerged fermentation consists of a controlled agitation and aeration of the must in which the obligate aerobic bacteria oxidise ethanol into acetaldehyde and then into acetic acid.

The process of acetic acid fermentation involves several bacterial genera, such as Acetobacter, Gluconobacter, Gluconacetobacter and Komagataeibacter $(10,11)$. In an ad-hoc designed fermentor, the combination of agitation and aeration promotes the formation of microbubbles of air that facilitate the diffusion of oxygen, which increases the contact surface between the bacteria and the substrate, in turn, boosting the efficiency and productivity of the fermentation. The absence of aeration for even 1 min during this process can result in eight consecutive non-productive days of fermentation (12).

In the production of vinegar with a high content of acetic acid, the fermentation is typically a semi-continuous process, which operates in cycles. The cycle starts with a total volume fraction of broth ranging from 12 to $15 \%$ (7-10\% acetic acid and $5 \%$ ethanol). When the ethanol volume fraction is between 0.2 and $0.3 \%$, a relative volume of fermented broth is withdrawn, and a new volume is added to the medium (13).

In order to expand the use of soybean molasses, this work aims to identify the best parameters for the cycles of acetic acid fermentation of soybean molasses by the submerged semi-continuous process and, secondly, to characterise the obtained vinegar.

\section{MATERIALS AND METHODS}

\section{Material}

The ethanol from soybean molasses used for the production of vinegar was obtained in a previous work (1). It had an alcohol content of $6.00 \%(V / V)$ and acidity of $7.40 \mathrm{~g} / \mathrm{L}$ (acetic acid). Isoflavone standards were obtained from Wako Pure Chemical Industries, Ltd. (Osaka, Japan) and Sigma-Aldrich Co., Merck (St. Louis, MO, USA). All other reagents were of analytical grade and sourced commercially from various manufacturers as stated in the following chapters.

\section{Inoculum activation and preparation}

Pure cultures of acetic acid bacteria (AAB) were not used for the production of vinegar in this work because the environmental conditions, such as low $\mathrm{pH}$, presence of ethanol, aeration and temperature, naturally select the best producer species. The mixed culture of $A A B$ was obtained during the production of unfiltered white vinegar, according to Spinosa (14) with modifications. This material was quickly collected from the German fermentor of a vinegar-producing industry (Tecnologia em Saúde, Assis, Brazil). This fermentor had a total capacity of $300 \mathrm{~L}$ and operated at $30^{\circ} \mathrm{C}$ with $1.0 \%(V / V)$ ethanol and $40 \%(\mathrm{~m} / \mathrm{V})$ total titratable acidity. To obtain the initial inoculum, $50 \mathrm{~mL}$ of white vinegar were added to a flask containing $250 \mathrm{~mL}$ of mannitol-yeast broth (HiMedia, Mumbai, India) and placed in a shaking incubator (CT-712 R; Cientec, Belo Horizonte, Brazil) at $30^{\circ} \mathrm{C}$ for $72 \mathrm{~h}$. This initial inoculum was transferred to a bioreactor holding vessel containing $4 \mathrm{~L}$ of a broth prepared with a mixture of $2 \mathrm{~L}$ of unfiltered white vinegar containing $10.0 \%$ acetic acid $(\mathrm{m} / \mathrm{V})$ and $0.4 \mathrm{~L}$ ethanol with $50.0 \%$ alcohol $(V / V)$, which contained a bacterial count equal to or greater than $8 \log C F U / m L$.

\section{Acetic acid fermentation}

The bioreactor ( $6 \mathrm{~L}$ total volume) used for soybean molasses vinegar production in submerged fermentation at the pilot scale was a Rubia Basic; Biofoco, Piracicaba, Brazil. The conditions of the fermentation process in the bioreactor were $(30 \pm 0.5)^{\circ} \mathrm{C}$, agitation $800 \mathrm{rpm}$, aeration flow $0.50 \mathrm{~L} / \mathrm{min}$ and aeration flow through culture medium $0.25 \mathrm{~L} /(\mathrm{mL} \cdot \mathrm{min})$. During the process, the total acidity, alcohol content and aeration were adjusted, as the acidity and alcohol content are the determining parameters for loading and unloading the fermentation cycles. The total volume fraction of the initial broth was defined as the sum of the fractions of ethanol and acetic acid (in \%). Therefore, the total initial broth (10\%) contained $5 \%(V / V)$ ethanol and $5 \%(\mathrm{~m} / \mathrm{V})$ acetic acid. The cycles of submerged acetic acid fermentation were conducted as a fed-batch and each one of these cycles is considered as a replicate of the experiment. When the alcohol content reached $0.5 \%(V / V)$, an aliquot of the vinegar volume was withdrawn from the reactor and the same volume of ethanol from soybean molasses was added.

\section{Acetic acid fermentation of ethanol from soybean molasses}

After the conditions had stabilised, $0.680 \mathrm{~L}$ ethanol obtained from alcoholic fermentation of soybean molasses previously centrifuged (model 5804R; Eppendorf, Hamburg, Germany) at $12000 \times g$ and $4{ }^{\circ} \mathrm{C}$ for $15 \mathrm{~min}$ was added to the bioreactor. Thus, the initial content of ethanol reached 1.52 $\%(V / V)$.

Once the fermentation cycles had started, the vinegar was collected when the ethanol volume fraction in the vinegar reached $\varphi \leq 0.5 \%$. In order to maintain the total volume fraction of the broth, an adequate volume of the ethanol had 
to be replaced. To evaluate the most suitable parameters for the acetic acid fermentation of ethanol from soybean molasses, eight fermentation cycles were performed. The first five cycles were performed to facilitate culture adaptation, whereas during the last three cycles, the reactor only contained the acetic acid and the alcohol-fermented soybean molasses. For each cycle, the following parameters were determined: acetic acid fermentation yield $\left(Y_{\mathrm{AA}}\right)$, total yield of acetic acid in the broth $\left(Y_{A A}(\right.$ broth $\left.)\right)$ and productivity of acetic acid $\left(P_{\mathrm{AA}}\right)$. These parameters were calculated using the following equations, respectively:

$$
\begin{gathered}
Y_{\mathrm{AA}}=\gamma_{\mathrm{f}} \cdot 0.77 \cdot 100 / V_{\mathrm{R}} \\
Y_{\mathrm{AA}}(\text { broth })=\varphi_{\mathrm{AAf}} \cdot 100 / \varphi_{\mathrm{AAi}} \\
P_{\mathrm{AA}}=\left(V_{\mathrm{f}} \cdot \gamma_{\mathrm{f}} / t \cdot V_{\mathrm{R}}\right) \cdot 10
\end{gathered}
$$

where $\gamma_{\mathrm{f}}$ is the final acetic acid concentration $(\mathrm{g} / 100 \mathrm{~mL})$, 0.77 is the stoichiometric factor for conversion of ethanol to acetic acid, $V_{\mathrm{R}}$ is the volume of the reactor, $\varphi_{\text {AAi }}$ and $\varphi_{\text {AAf }}$ are the initial and final total volume fraction of acetic acid in the broth at the beginning and the end of the cycle (\%), $V_{f}$ is the volume $(\mathrm{L})$ of removed vinegar and $t$ is the time $(\mathrm{h})$ of fermentation cycle.

\section{Characterisation of soybean molasses vinegar}

The produced soybean molasses vinegar was distilled using an alcohol microdistiller (TE-012; Tecnal, Piracicaba, Brazil), and the dry extract and ash contents were determined gravimetrically using an oven (Odontobrás EL 1.5; Ribeirão Preto, Brazil) at $105^{\circ} \mathrm{C}$ and a muffle (Quimis, Diadema, Brazil) at $550^{\circ} \mathrm{C}$, respectively. The acidity of the distilled vinegar was determined by titration with $0.1 \mathrm{M} \mathrm{NaOH}$ (Química Moderna, Barueri, Brazil), using $1.0 \%$ phenolphthalein (Inlab, Diadema, Brazil) as an indicator, and it was expressed in $\mathrm{g}$ acetic acid per $100 \mathrm{~mL}$ solution. The ethanol content and relative density of the distilled vinegar were determined using a digital density meter (DDM 2909; Rudolph Research Analytical, Hackettstown, NJ, USA) at $20^{\circ} \mathrm{C}$ and expressed in $\mathrm{mL} / \mathrm{L}$ and $\mathrm{g} / \mathrm{cm}^{3}$ respectively.

Total sugar content of the vinegar was determined according to DuBois et al. (15) in a spectrophotometer (Spectronic Genesys 6; Thermo Electronic Corporation, Waltham, MA, USA) at $490 \mathrm{~nm}$ using glucose (Synth, Diadema, Brazil) as standard. Total phenolic content was determined in a spectrophotometer (Spectronic Genesys 6; Thermo Electronic Corporation) at $760 \mathrm{~nm}$ with Folin-Ciocalteu reagent (Sigma-Aldrich Co., Merck). The results were expressed in $\mathrm{mg}$ gallic acid (Sigma-Aldrich Co., Merck) equivalents per $100 \mathrm{~mL}$ of the sample, as described by Singleton et al. (16).

To separate the different isoflavone forms present in the vinegar, we used a 1:1:1 volume ratio of ultrapure water (Merck Millipore, Burlington, MA, USA), acetone (Anidrol, Diadema, Brazil) and ethanol (Anidrol). The extracts were homogenized every $15 \mathrm{~min}$ for $1 \mathrm{~h}$ on a tube shaker (CT-712 R; Cientec), followed by sonication (Solidsteel, Piracicaba, Brazil) for $15 \mathrm{~min}$ and centrifugation (model 5804R; Eppendorf) at 794×g and $4{ }^{\circ} \mathrm{C}$ for $15 \mathrm{~min}$. The supernatants were filtered using a 0.22 $\mu \mathrm{m}$ polyvinylidene fluoride (PVDF) membrane (Millex ${ }^{\circledR}$, Millipore, Sigma-Aldrich Ireland Ltd., Merck, Arklow, Ireland) and analyzed by ultra-performance liquid chromatography (Acquity UPLC System, Waters, Milford, MA, USA), as described by Handa et al. (5).

\section{Cell count}

The $A A B$ used in the soybean molasses vinegar production were quantified by plate counting after allowing them to grow on a double layer of mannitol, yeast and peptone agar (HiMedia) (0.50 and $1.00 \%$ agar in the lower and upper layer, respectively) at $30{ }^{\circ} \mathrm{C}$ for $48 \mathrm{~h}$. The counts were expressed in CFU/mL (14).

\section{Statistical analysis}

Three independent assays were performed, and the average values were determined. Data are expressed as mean value \pm standard deviation using the statistical software $R \mathrm{v}$. 3.5.3 (17).

\section{RESULTS AND DISCUSSION}

\section{Evaluation of the parameters used for the acetic acid fermentation of ethanol from soybean molasses}

The conversion rate of acetic acid (Table 1) decreased with the addition of the alcohol fermentation product from soybean molasses into the fermentor. The same was also observed for the productivity $\left(P_{\mathrm{AA}}\right)$, which decreased considerably after the fourth cycle, starting with $0.106 \mathrm{~g} /(\mathrm{L} \cdot \mathrm{h})$ in the first cycle and decreasing to $0.023 \mathrm{~g} /(\mathrm{L} \cdot \mathrm{h})$ in the final cycle. This decrease can be related to the fact that soybean molasses ethanol contained considerable amounts of residual sugars (Table 2). In some AAB species, two main metabolic pathways are present: the pentose phosphate cycle for carbohydrate oxidation and the tricarboxylic acid cycle for the oxidation of organic acids (18). Due to the considerable amount of sugars in soybean molasses ethanol, a change in the metabolic pathway by the AAB might have occurred, which affected the productivity results. In this case, the microbiota could have prioritised the carbohydrate metabolism pathway, producing less acetic acid (product of ethanol metabolism) and more carbohydrate metabolism products, such as gluconic acid or exopolysaccharides (cellulose, levan, dextran or acetan) (19). In the conversion of ethanol into acetic acid, various intermediate compounds, including acetaldehyde, ethyl acetate and other alcohols, esters and acids, are also formed. Their nature and quantity depend on the characteristics of the raw material (wine) and they are responsible for the flavour of the vinegar (14). 
Table 1. Cycles and parameters of acetic fermentation of soybean molasses

\begin{tabular}{|c|c|c|c|c|c|c|c|c|c|c|c|c|c|}
\hline Cycle & $\frac{t}{\mathrm{~h}}$ & $\frac{V_{B}}{L}$ & $\frac{\varphi(\text { ethanol })_{i}}{\%}$ & $\frac{\gamma_{\mathrm{i}}}{\mathrm{g} / \mathrm{L}}$ & $\frac{\varphi_{\mathrm{AAi}}}{\%}$ & $\frac{V_{A}}{L}$ & $\frac{V_{R}}{L}$ & $\frac{\gamma_{f}}{g / L}$ & $\frac{\varphi(\text { ethanol })_{\mathrm{f}}}{\%}$ & $\frac{\varphi_{\text {AAf }}}{\%}$ & $\frac{Y_{\mathrm{AA}}}{\%}$ & $\frac{Y_{\mathrm{AA}}(\text { broth })}{\%}$ & $\frac{P_{\text {AA }}}{g /(L \cdot h)}$ \\
\hline 1 & 49 & 4.30 & 1.52 & 56.20 & 7.14 & 0.68 & 0.50 & 62.40 & 0.30 & 6.54 & 80.08 & 91.60 & 0.106 \\
\hline 2 & 48 & 4.18 & 1.48 & 53.10 & 6.79 & 0.50 & 0.50 & 58.00 & 0.50 & 6.30 & 74.43 & 92.78 & 0.101 \\
\hline 3 & 48 & 3.98 & 1.50 & 55.60 & 7.06 & 0.50 & 0.50 & 59.00 & 0.50 & 6.40 & 74.72 & 90.65 & 0.102 \\
\hline 4 & 54 & 3.88 & 1.41 & 50.60 & 6.47 & 0.50 & 0.50 & 58.00 & 0.20 & 6.00 & 73.43 & 92.74 & 0.090 \\
\hline 5 & 110 & 4.43 & 1.16 & 50.00 & 6.16 & 0.80 & 0.80 & 55.00 & 0.30 & 5.80 & 70.58 & 94.16 & 0.067 \\
\hline 6 & 50 & 4.40 & 1.74 & 42.60 & 6.00 & 0.60 & 0.30 & 51.00 & 0.70 & 5.80 & 65.45 & 96.67 & 0.051 \\
\hline 7 & 91 & 4.30 & 1.86 & 45.00 & 6.36 & 0.50 & 0.30 & 49.00 & 0.40 & 5.38 & 62.88 & 84.59 & 0.027 \\
\hline 8 & 77 & 3.80 & 1.18 & 43.50 & 5.53 & - & 0.20 & 52.00 & 0.50 & 5.70 & 66.73 & 97.92 & 0.023 \\
\hline Average* & 73 & 4.17 & 1.59 & 43.70 & 5.96 & - & - & 50.70 & 0.56 & 5.63 & 65.02 & 92.76 & 0.033 \\
\hline
\end{tabular}

$t=$ fermentation time, $V_{\mathrm{B}}=$ volume of the bioreactor, $\varphi$ (ethanol) ${ }_{\mathrm{i}}$ and $\varphi(\text { ethanol })_{\mathrm{f}}=$ initial and final volume fraction of ethanol, $\gamma_{\mathrm{i}}=$ initial acidity, $\varphi_{\mathrm{AAi}}$ and $\varphi_{\mathrm{AAf}}=$ initial and final volume fraction of acetic acid in the broth, $V_{\mathrm{A}}=$ volume of fermented broth (alcohol) added to the fermentor, $V_{\mathrm{R}}=$ volume of the removed acetic acid, $\gamma_{\mathrm{f}}=$ final acidity, $Y_{\mathrm{AA}}=y$ ield of acetic acid, $Y_{\mathrm{AA}}$ (broth)=total yield of acetic acid in the broth, $P_{\mathrm{AA}}=$ productivity. ${ }^{*}$ Average value of the last three cycles

Table 2. Physicochemical characterisation of the soybean molasses vinegar

$\begin{array}{lc}\text { Component } & \text { Value } \\ \text { Acidity } /(\mathrm{g} / 100 \mathrm{~mL}) & 5.07 \pm 0.06 \\ (m(\text { residual ethanol }) / V(\text { vinegar })) \% & 0.34 \pm 0.02 \\ (m(\text { residual sugar }) / V(\text { vinegar })) / \% & 7.86 \pm 0.12 \\ (m(\text { dry extract }) / V(\text { vinegar })) \% & 14.67 \pm 0.07 \\ (m(\text { ash }) / V(\text { vinegar })) / \% & 2.27 \pm 0.10 \\ \rho_{\text {relative }} /\left(\mathrm{g} / \mathrm{cm}^{3}\right) & 1.02 \pm 0.00\end{array}$

The average time required for the acetification of soybean molasses (mean of the last three cycles) was $73 \mathrm{~h}$ (Table 1 ). Among these three fermentation cycles (which contained only the fermented broth and ethanol from soybean molasses), the shortest fermentation time was $50 \mathrm{~h}$ (sixth cycle) and the longest was $91 \mathrm{~h}$ (seventh cycle). The highest acidity level and $Y_{\mathrm{AA}}(52.00 \mathrm{~g} / \mathrm{L}$ and $66.73 \%$, respectively) were reached after $77 \mathrm{~h}$ (eighth cycle). Spinosa et al. (8) produced vinegar from rice wine in a submerged fermentation and evaluated 10 fermentation cycles. During this process, the wine from alcohol fermentation contained $62.80 \mathrm{~g} / \mathrm{L}$ ethanol, which produced a vinegar with an acetic acid content $65.80 \mathrm{~g} / \mathrm{L}$, $Y_{\mathrm{AA}}=86.00 \%$ and $0.70 \mathrm{~g} / \mathrm{L}$ acetic acid yield. In another work that aimed to obtain a vinegar from banana pulp, Tanaka et al. (20) recorded a maximal concentration of acetic acid ranging from 59.0 to $40.0 \mathrm{~g} / \mathrm{L}$, with an average of $49.7 \mathrm{~g} / \mathrm{L}$. At the end of our fermentation, the acidity, $Y_{\mathrm{AA}}$ and productivity were $50.70 \mathrm{~g} / \mathrm{L}, 65.02 \%$ and $0.033 \mathrm{~g} /(\mathrm{L} \cdot \mathrm{h})$, respectively, on average, over the last three cycles (Table 1).

The acetic acid production by the oxidation of ethanol is an exothermic reaction that requires oxygen. Consequently, the fermentation efficiency is highly related to the aeration and the air dispersion rates inside the reactor. The low productivity $\left(P_{\mathrm{AA}}\right)$ observed in this work may also be associated with the non-homogeneous air distribution inside the fermentor. Other authors observed the same occurrence $(8,12)$. Another problem that can cause a low acetic acid yield is the evaporation of ethanol. This loss occurs during fermentation and can reach up to $10-30 \%$ of the stoichiometric yield, depending on the temperature. A study of open, semi-open and closed acetic acid fermentor concluded that closed acetic acid fermentor is more appropriate for industry because of lower loss by evaporation (14).

\section{Characterisation of the vinegar}

The acetic acid fermentation product of soybean molasses contained, on average, $5.07 \%(\mathrm{~m} / \mathrm{V})$ acetic acid, $0.34 \%(\mathrm{~m} / \mathrm{V})$ residual ethanol, $14.67 \%(\mathrm{~m} / \mathrm{V})$ dry extract, $2.27 \%(\mathrm{~m} / \mathrm{V})$ ash, and had a density of $1.02 \mathrm{~g} / \mathrm{cm}^{3}$ (Table 2). According to the legislation of some countries like Brazil, the minimum acidity levels required for the commercialisation of vinegar is $40 \mathrm{~g} / \mathrm{L}$ (8). In this context, the acetic acid fermentation product obtained during this project conforms to the standards.

Different alcohol (ethanol) and acetic acid (vinegar) fermentation products with unique chemical characteristics can be obtained from different raw materials. For this reason, we analysed the contents of the total phenolic compounds and isoflavones of the products obtained from soybean molasses fermented with alcohol (ethanol) and acetic acid (vinegar) (Table 3). High concentrations of total phenolic compounds were observed in soybean molasses, ethanol and vinegar that were 1.52-, 61.0- and 53.9-fold higher than the total isoflavone content, respectively. Total phenolic content of the alcoholic (ethanol) and acetic acid (vinegar) fermentation products from soybean molasses decreased by 3.49 and $35.69 \%$, respectively. However, when the alcohol fermentation was extended into the acetic acid fermentation, the total phenolic content decreased to $37.86 \%$. The high concentration of total phenolic compounds of the ethanol and vinegar derived from soybean molasses might have been caused by the retention of some of these compounds during fermentation. Specifically, during alcohol fermentation new compounds could have been generated as a result of the presence of microorganisms (21).

The total isoflavone content of soybean molasses (Table 3 ) was high, whereas during the alcohol and acetic acid fermentations, the content decreased to 38.8 and $55.64 \%$, respectively. The total isoflavone content decreased only 1.42 times as the alcohol fermentation progressed into the acetic acid fermentation. In soybean molasses, the predominant forms of 
Table 3. Contents of total phenolics (in $\mathrm{mg} \mathrm{GAE}$ per $100 \mathrm{~mL}$ ) and isoflavones (in $\mathrm{mg}$ per $100 \mathrm{~mL}$ on wet mass basis) in soybean molasses, wine (alcohol fermentation) and vinegar (acetic acid fermentation)

$\begin{array}{lccc}\text { Fermentation product } & \text { Soybean molasses } & \text { Wine } & \text { Vinegar } \\ \text { Total phenolics } & 625 \pm 59 & 647 \pm 10 & 402 \pm 4 \\ \text { 6"-O-Malonyl-daidzin } & 12.0 \pm 0.6 & \text { n.d. } & \text { n.d. } \\ \text { 6"-O-Malonyl-genistin } & 10.4 \pm 0.3 & \text { n.d. } & \text { n.d. } \\ \text { Daidzin } & 125.8 \pm 2.0 & \text { n.d. } & \text { n.d. } \\ \text { Genistin } & 186.2 \pm 9.3 & 3.8 \pm 0.4 & 3.0 \pm 0.2 \\ \text { Glycitin } & 29.8 \pm 1.0 & 4.6 \pm 1.0 & 3.2 \pm 0.2 \\ \text { Daidzein } & 22.4 \pm 1.1 & 2.2 \pm 0.4 & 1.29 \pm 0.06 \\ \text { Genistein } & 25.2 \pm 0.6 & \text { n.d. } & \text { n.d. } \\ \text { Total isoflavones } & 411.8 \pm 14.0 & 10.6 \pm 1.8 & 7.5 \pm 0.5\end{array}$

$\mathrm{GAE}=$ gallic acid equivalents, $\mathrm{n} \cdot \mathrm{d} .=$ not detected

isoflavones were $\beta$-glycosides, aglycones and malonylglycosides at $83.01,11.55$ and $5.43 \%$, respectively, and no acetylglycosides were detected. This result is interesting because these values report a very different isoflavone profile compared to soybean grain. Moreover, the absence of acetylglycoside isoflavones indicates that soybean molasses did not undergo any high thermal treatment during its production.

The predominant isoflavones of the 18 soybean cultivars investigated by Ribeiro et al. (22) were malonyldaidzin and malonylgenistin and together they accounted for 67.0 $\%$ of the total isoflavone content. In the same study, there were $31.0 \% \beta$-glycosides and $2.0 \%$ aglycones among total isoflavones, whereas the acetylated form was not detected. When heat-treated in an oven at $200^{\circ} \mathrm{C}$ for $20 \mathrm{~min}$, whole soybean meal showed an altered isoflavone content and a high conversion rate of malonylglycosides to acetylglycosides, $\beta$-glycosides and aglycones (23). Malonylgenistin has been described as the predominant isoflavone in soybean, and it can be converted to acetylgenestin or genistin after drying or hot-water extraction, respectively. Humid heat is more effective than dry heat to convert and degrade the isoflavones mentioned above (24). The contents of 6"-O-malonyl-daidzin and 6"-O-malonyl-genistin were low in soybean molasses (Table 3), and after the alcoholic and acetic acid fermentation, these two forms were no longer detectable. Moreover, no $\beta$-glycosides (daidzin) or aglycones (genistein) could be detected in the ethanol and vinegar produced during our study. Instead, $\beta$-glycosides (genistin and glycitin) and aglycones (daidzein) were the only forms of isoflavones present in both fermented products, at low concentrations. The low amounts or lack of detection of isoflavones in ethanol and vinegar was probably caused by the presence of yeasts, which may utilise certain cell wall phenolic compounds, as observed by Razmkhab et al. (25). The defatted soybean meal fermented in the presence of Monascus purpureus or Aspergillus oryzae at an adequate water/ethanol ratio was considered the ideal method to simultaneously extract phenolic compounds and isoflavones with high antioxidant activities (26).

There is a growing interest among consumers and industries for the production of antioxidant-rich soy products (27). In this study, we obtained alcohol- and acetic acid-fermented products from soybean molasses with a unique chemical composition of total phenolic compounds and isoflavones. In particular, the presence of aglycones (daidzein) in our products is especially remarkable, as these compounds are deemed highly beneficial to human health.

\section{CONCLUSIONS}

The current study demonstrated that soybean molasses could be used to produce vinegar. Moreover, based on our results, each tonne of soybean molasses can produce an estimated $3460 \mathrm{~L}$ of vinegar, with an acetic acid concentration of 40 $\mathrm{g} / \mathrm{L}$, which is equivalent to $139 \mathrm{~kg}$ of acetic acid and satisfies the minimum concentration required by the legislation on vinegar production. Additional studies should be carried out to improve the fermentation conditions and thereby increase productivity, while simultaneously reducing the extent of the acetic acid fermentation. Furthermore, for soybean molasses to be proposed for human consumption, a profile of the antinutritional factors and some sensorial studies still need to be performed.

\section{ACKNOWLEDGEMENTS}

The authors would like to thank the Universidade Estadual de Londrina and the Coordenação de Aperfeiçoamento de Pessoal de Nível Superior (CAPES) for the scholarship awarded to the first author, and the Conselho Nacional de Desenvolvimento Científico e Tecnológico (CNPq) for its financial support (Grant numbers: 431206/2016-3, and 313769/2017-6), and the EMBRAPA (Grant number: SEG 02.14.03.012.00.00) during the execution of this project.

\section{CONFLICT OF INTEREST}

The authors have no conflicts of interest to declare.

\section{ORCID ID}

L.C.R. Miranda (1) https://orcid.org/0000-0003-2810-3282

R.J. Gomes 1 https://orcid.org/0000-0002-5150-0262

J.M.G. Mandarino (1) https://orcid.org/0000-0002-2197-9727

E.I. Ida @ https://orcid.org/0000-0002-5128-6366

W.A. Spinosa (1) https://orcid.org/0000-0001-9532-0135 


\section{REFERENCES}

1. Caldeirão L, Tanaka C, Ida E, Spinosa W. Modeling and kinetic study of bio-ethanol production from soy protein concentrate by-product. Food Sci Technol (Campinas). 2016;36(2):369-74.

https://doi.org/10.1590/1678-457X.0021

2. Hosny M, Rosazza JPN. Novel isoflavone, cinnamic acid, and triterpenoid glycosides in soybean molasses. J Nat Prod. 1999;62(6):853-8.

https://doi.org/10.1021/np980566p

3. Romão BB, da Silva FB, de Resende MM, Cardoso VL. Ethanol production from hydrolyzed soybean molasses. Energ Fuel. 2012;26(4):2310-6. https://doi.org/10.1021/ef201908j

4. Handa CL, de Lima FS, Guelfi MFG, Fernandes MS, Georgetti SR, Ida El. Parameters of the fermentation of soybean flour by Monascus purpureus or Aspergillus oryzae on the production of bioactive compounds and antioxidant activity. Food Chem. 2019;271:274-83.

https://doi.org/10.1016/j.foodchem.2018.07.188

5. Handa CL, Couto UR, Vicensoti AH, Georgetti SR, Ida El. Optimisation of soy flour fermentation parameters to produce $\beta$-glucosidase for bioconversion into aglycones. Food Chem. 2014;152:56-65.

https://doi.org/10.1016/j.foodchem.2013.11.101

6. Uysal RS, Soykut EA, Boyaci IH, Topcu A. Monitoring multiple components in vinegar fermentation using Raman spectroscopy. Food Chem. 2013;141(4):4333-43. https://doi.org/10.1016/j.foodchem.2013.06.122

7. Yetiman AE, Kesmen Z. Identification of acetic acid bacteria in traditionally produced vinegar and mother of vinegar by using different molecular techniques. Int J Food Microbiol. 2015;204:9-16.

https://doi.org/10.1016/j.ijfoodmicro.2015.03.013

8. Spinosa WA, dos Santos Júnior V, Galvan D, Fiorio JL, Gomez RJHC. Vinegar rice (Oryza sativa L.) produced by a submerged fermentation process from alcoholic fermented rice. Food Sci Technol (Campinas). 2015;35(1):196-201.

https://doi.org/10.1590/1678-457X.6605

9. Štornik A, Skok B, Trček J. Comparison of cultivable acetic acid bacterial microbiota in organic and conventional apple cider vinegar. Food Technol Biotechnol. 2016;54(1):1139.

https://doi.org/10.17113/ftb.54.01.16.4082

10. Valera MJ, Torija MJ, Mas A, Mateo E. Acetic acid bacteria from biofilm of strawberry vinegar visualized by microscopy and detected by complementing culture-dependent and culture-independent techniques. Food Microbiol. 2015;46:452-62. https://doi.org/10.1016/j.fm.2014.09.006

11. Trček J, Mahnič A, Rupnik M. Diversity of the microbiota involved in wine and organic apple cider submerged vinegar production as revealed by DHPLC analysis and next-generation sequencing. Int J Food Microbiol. 2016;223:57-62.

https://doi.org/10.1016/j.ijfoodmicro.2016.02.007

12. Hitschmann A, Stockinger H. Oxygen deficiency and its effect on the adenylate system in Acetobacter in the submerse acetic fermentation. Appl Microbiol Biotechnol. 1985;22(1):46-9.

https://doi.org/10.1007/BF00252155

13. Gullo, M, Verzelloni E, Canonico M. Aerobic submerged fermentation by acetic acid bacteria for vinegar production: Process and biotechnological aspects. Process Biochem. 2014;49(10):1571-9.

https://doi.org/10.1016/j.procbio.2014.07.003

14. Spinosa WA. Selection, identification and kinetic parameters of acetic acid bacteria isolated from vinegar industry [PhD Thesis]. Campinas, Brazil: State University of Campinas; 2002 (in Portuguese).

15. DuBois M, Gilles KA, Hamilton JK, Rebers PA, Smith F. Colorimetric method for determination of sugars and related substances. Anal Chem. 1956; 28(3):350-6.

https://doi.org/10.1021/ac60111a017

16. Singleton VL, Orthofer R, Lamuela-Raventós RM. Analysis of total phenols and other oxidation substrates and antioxidants by means of Folin-Ciocalteu reagent. Method Enzymol. 1999;299:152-78.

https://doi.org/10.1016/S0076-6879(99)99017-1

17. $\mathrm{R}$ Core Team. The $\mathrm{R}$ project for statistical computing. $\mathrm{R}$ Foundation for Statistical Computing, Vienna, Austria; 2014. Available from: http://www.R-project.org/.

18. Huang Y, Zhu C, Yang J, Nie, Y, Chen C, Sun D. Recent advances in bacterial cellulose. Cellulose. 2014;21(1):1-30. https://doi.org/10.1007/s10570-013-0088-z

19. Gomes RJ, de Borges MF, Rosa MF, Castro-Gómez RJH, Spinosa WA. Acetic acid bacteria in the food industry: Systematics, characteristics and applications. Food Technol Biotechnol. 2018;56(2):139-151.

https://doi.org/10.17113/ftb.56.02.18.5593

20. Tanaka CA, Ruzon FI, Miranda LCR, Galvan D, Spinosa WA, Castro-Goméz RJH. Modeling and kinetics of bioconversion and chemical properties (wine and vinegar) from banana pulp by-products. Preprints. 2016; 2016120007. https://doi.org/10.20944/preprints201612.0007.v1

21. Lee JH, Cho HD, Jeong JH, Lee MK, Jeong YK, Shim KH, Seo $\mathrm{KI}$. New vinegar produced by tomato suppresses adipocyte differentiation and fat accumulation in 3T3-L1 cells and obese rat model. Food Chem. 2013;141(3):3241-9. https://doi.org/10.1016/j.foodchem.2013.05.126

22. Ribeiro MLL, Mandarino JMG, Carrão-Panizzi MC, de Oliveira MCN, Hoffman-Campo CB, Nepomuceno AL, Ida El. Isoflavone content and $\beta$-glucosidase activity in soybean cultivars of different maturity groups. J Food Compos Anal. 2007;20(1):19-24.

https://doi.org/10.1016/j.jfca.2006.07.004 
23. Andrade JC, Mandarino JMG, Kurozawa LE, Ida El. The effect of thermal treatment of whole soybean flour on the conversion of isoflavones and inactivation of trypsin inhibitors. Food Chem. 2016;194:1095-101.

https://doi.org/10.1016/j.foodchem.2015.08.115

24. Chien JT, Hsieh HC, Kao TH, Chen BH. Kinetic model for studying the conversion and degradation of isoflavones during heating. Food Chem. 2005;91(3):425-34.

https://doi.org/10.1016/j.foodchem.2004.06.023

25. Razmkhab S, Lopez-Toledano A, Ortega JM, Mayen M, Merida J, Medina M. Adsorption of phenolic compounds and browning products in white wines by yeasts and their cell walls. J Agric Food Chem. 2002;50(25):7432-7.

https://doi.org/10.1021/jf025733c

26. Handa CL, de Lima FS, Guelfi MFG, Georgetti SR, Ida El. Multi-response optimisation of the extraction solvent system for phenolics and antioxidant activities from fermented soy flour using a simplex-centroid design. Food Chem. 2016;197(Pt A):175-84.

https://doi.org/10.1016/j.foodchem.2015.10.124

27. Song $X$, Xue $Y$, Wang $Q$, Wu X. Comparisson of three termostable $\beta$-glucosidases for application in the hydrolysis of soybean isoflavone glycosides. J Agric Food Chem. 2011;59(5):1954-61.

https://doi.org/10.1021/jf1046915 